\title{
A Survay on Photovoltaics Technology for Water Pumping
}

\author{
Matt Bowden \\ Computer Science and Engineering, Australian National University, Australia. \\ mat.den@outlook.com
}

\section{ArticleInfo}

Journal of Machine and Computing (http://anapub.co.ke/journals/jmc/jmc.html)

Doi : https://doi.org/10.53759/7669/jmc202101010

Received 20 December 2020; Revised form 26 January 2021; Accepted 25 March 2021; Available online 05 April 2021. (C)2021 The Authors. Published by AnaPub Publications.

This is an open access article under the CC BY-NC-ND license. (http://creativecommons.org/licenses/by-nc-nd/4.0/)

\begin{abstract}
Due to the evident shortfalls in the high costs of diesel and current, the requirements of pumping for agricultural and aqua supply have been affected. In that regard, utilizing solar energy to pump aqua is a potential technology for diesel-driven and conventional propelling structures. Propelling aqua using solar energy is done using photovoltaics techniques that transform energy from the sun into useful power meant to operate AC or DC engine-driven hydraulic ram. This research contribution provides a critical evaluation of the solar propelling technology e.g. Maximum Power-Point Trackers (MPPTs) and is based on economic viabilities of solar photovoltaics techniques and schemes, execution evaluation, photovoltaics generator degradation, and optimum sizing that distributes power to the electropumps. This analysis also relates to environmental and economic aspects, advanced Photovoltaics materials, and potential enhancements. Updates regarding the present condition and usage of solar $\mathrm{H} 2 \mathrm{O}$ propelling technologies have also been focusing in this analysis.
\end{abstract}

Keyword - Maximum Power Point Trackers (MPPTs), Alternating Current (AC), Direct Current (DC)

\section{INTRODUCTION}

For decades now, $\mathrm{H} 2 \mathrm{O}$ propelling has been a prevailing concern among engineers and industries hence has stimulated the introduction of methods for propelling. Various sources of power have been utilized: wind, fuels e.g. diesel, solar, hydropower, and human energy. The most typical form of electropumps utilized in remote communities includes directdrive diesel-based borehole pump, hand pump, power-driven immersed pump with diesel generators, and solar immersed pump, including photovoltaics. Table 1 below represents the advantages and disadvantages of different propelling techniques.

The execution parameter of electropumps fundamentally depends on the rate of flow of water that is based on the conditions of weather at a particular location mostly irradiance of solar and air temperature variation. Execution of electropumps is based on the requirement of water, sizes of water storage tanks, heads $(\mathrm{m})$ via which lifting of aqua is achieved, aqua volumes being pumped $\left(\mathrm{m}^{3}\right)$, the array of virtual power for photovoltaics $(\mathrm{kWh})$. Power at electropumps $(\mathrm{kWh})$, unutilized efficiency in \%, and diurnal variations in the pressure of the electropumps result in the transformation of pressure and irradiance compensation.

Photovoltaics technological efficiency utilized in photovoltaics generators have also a significant effect on execution. Other than that, the degradation of photovoltaics panels is a critical parameter, which stimulates the execution of solar energy electropumps. This form of execution of these photovoltaics schemes is guided using particular parameters:

- Existence of radiations from the sun at a particular position

- Overall dynamic heads - the summation of heads and heights from suction points to the main pump, heads of discharge (heights from electropumps to the inlets of storage), and the frictional loss

- $\quad$ Rate of flow of aqua

- The overall quantity of aqua requirements; and

- Hydraulic power, which is potential power essential in raising water to the discharged levels

To assess the technology of photovoltaics $\mathrm{H} 2 \mathrm{O}$ propelling, different research works have been analyzed and summarized in the literature review section. Photovoltaics water-siphoning schemes have shown fundamental enhancement over the past few decades. The demerits in the designing of electropumps started its introduction in the 1970s. This shows that they have been eliminated by now. The use and application of electronic structures have graduated now and output energies, execution, and reliability of these structures have now advanced. Their applications are now evident in community aqua supply projects, agricultural projects, drinking applications, etc. AC and DC engines based on hydraulic efficacy varied from $24 \%$ to $34 \%$ whereby the $2^{\text {nd }}$ generation of photovoltaics schemes used positive aspects of the 
displacement pump running the 1 st generation photovoltaics siphoning schemes for radial electropumps. Controllers were utilized to monitor the level of the storage tank and the velocity of electropumps. Maximum Power-Point Trackers (MPPTs) technology is utilized in the optimization of $\mathrm{H} 2 \mathrm{O}$ propelling. Directly fixed Direct Current (DC) electropumps without storage of batteries are still pocket-friendly, reliable, and easier for small-scale projects of agricultural. However, they do not facilitate the operation of MPPT for photovoltaics generators.

Nonetheless, adding MPPTs and projections/controls can further enhance the execution of photovoltaics electropumps. J. Roger and C. Maguin in [1] have developed some simulation programs for execution forecast of photovoltaics $\mathrm{H} 2 \mathrm{O}$ propelling scheme concerning data on solar radiation and location of the real photovoltaics electropumps. With optimal sizing method, it leads to the selection of different refinements and components of photovoltaics siphoning technologies from manufacturers. Fluctuations in the dust accumulation, solar irradiance on photovoltaics generators, and higher module temperature affect the overall executions of photovoltaics structures.

Water that is sprayed in photovoltaics components results in spring-cleaning clouds of dust and cooling of the components hence improving the efficiency of the components, which also advances the rate of aqua flow. The aspects require adherence to enhance execution. Degradation evaluation of the photovoltaics module of the electropumps is fundamental and has to be done since it identifies the degradation method. Field researches on photovoltaics schemes done during the past four decades indicate that the mean energy degradation in photovoltaics module is about $1 \%$ per annum [2]. The energy produced is minimized photovoltaics module degradation of the generator because of prolonged exposures in fields, therefore necessitating the selection of effective photovoltaics technologies.

Comprehending the mechanisms of degradation and evaluating the lifetime of components are fundamental areas of research for photovoltaics $\mathrm{H} 2 \mathrm{O}$ propelling since it attracts the attention of many engineers. Photovoltaics generators are a major element of solar hydraulic ram. Therefore, the selections of the best photovoltaics techniques are critical for the execution of pups and the reliability of photovoltaics schemes. The application of cells of photovoltaics with the materials of higher efficiencies will possibly minimize the number of components, overall costs of installation, and the space required for installations. This, therefore, lowers the general costs of solar power compared to the costs incurred for current and fossil fuels.

Therefore, even the overall expenses of photovoltaics cell techniques with a higher degree of efficiency can be pocketfriendly at photovoltaics schemes and the levels of components than the lower efficiency cells. Photovoltaics schemes for water propelling can be developed concerning their optimized sizes regarding MPPT and the structure controllers. The optimal photovoltaics array, concerning a particular dimension is a critical factor that possibly enhances the general execution process of photovoltaics that could also be incorporated seasonally in a particular location. Maximized radiations from the sun on the panels that use optimal tilted angles enhance output energy from photovoltaics panels utilizing the structure.

A wider position of photovoltaics siphoning scheme utilizes dual-axis manual tracker, which can boost the efficacy of the structure up to about $18 \%$. The application of automated sun tracking enhances the efficiency of the put; however, incorporates significant costs of the photovoltaics scheme. The investment payback for photovoltaics schemes is about half a century, with several structures presenting paybacks in two years. Photovoltaics components are currently in various sizes in well-established engineering firms. Some of the module structures have reported paybacks in mid-time.

Photovoltaics reliability is such that manufacturers with life projections beyond 29 years provide a 19 to 24 -year energy warrant. With declines in photovoltaics module cost, warrant time of about 24 years, and incentives present for installing photovoltaics siphoning schemes in India, their payback time will be minimized further. Photovoltaics siphoning schemes are viable economically due to the urgent need for water in remote environments.

Nonetheless, the mismatch between the supply pattern of aqua and its plea has a significant influence on the economic viability of photovoltaics electropumps. In that case, the $\mathrm{H} 2 \mathrm{O}$ propelling project for the community has to be designed carefully. The determining dynamics influencing the widespread application of photovoltaics propelling techniques high investment costs and lack of users' awareness.

In this paper, we will evaluate the technology around photovoltaics hydraulic ram. Photovoltaics energy used in agricultural projects is pocket-friendly compared to the primitive sources of energy for small-scale propelling needs. With progressing the development of fossil fuels and their relatively high costs and reduced costs of watts for the photovoltaics cells due to high demand, photovoltaics power is viewed to be more economical over the next few years. Photovoltaicenergized structures are now applicable in agricultural and livestock production in communities and remote environments with limited access to conventional power. The literature review section focuses critically on the relevant sources for photovoltaics. It is seen that researchers have done execution evaluations, sizing methods, optimization, and efficiency enhancement, including the potential dynamics, which influence structure' executions, ecological and economical concepts of photovoltaics propelling schemes. 
Table 1: Advantages and disadvantages of propelling methods

\begin{tabular}{|c|c|c|}
\hline & Advantages & Disadvantages \\
\hline Hand propelling links & $\begin{array}{ll}\text { - } & \text { No costs of fuel } \\
\text { - } & \text { Low capital costs } \\
\text { - } & \text { Easy maintainability } \\
\text { - } & \text { Low manufacturing rates }\end{array}$ & $\begin{array}{l}\text { - Low rates of flow } \\
\text { - Insufficiency usage of } \\
\text { boreholes } \\
\text { - Low human productivity }\end{array}$ \\
\hline Animal-driven electropumps & $\begin{array}{l}\text { - Dung is used for cooking } \\
\text { - Low wages compared to } \\
\text { human } \\
\text { - Powerful than humans }\end{array}$ & 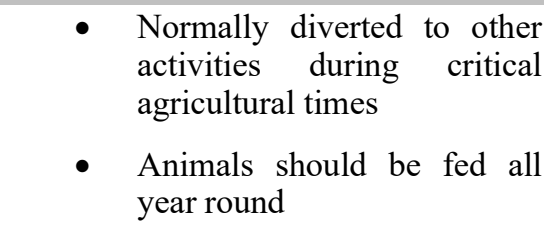 \\
\hline Hydraulic pump (e.g. rams) links & $\begin{array}{ll}\text { - } & \text { Higher reliability } \\
\text { - } & \text { Longevity } \\
\text { - } & \text { Low costs } \\
\text { - } & \text { Ease of maintainability } \\
\text { - } & \text { Unattended operations } \\
\text { - } & \text { No costs of fuels }\end{array}$ & $\begin{array}{l}\text { - Lower output } \\
\text { - Necessitate particular site } \\
\text { conditions and dynamics }\end{array}$ \\
\hline Windpump links & $\begin{array}{ll}\text { - } & \text { Unattended operations } \\
\text { - } & \text { Ease of maintainability } \\
\text { - } & \text { Longevity } \\
\text { - } & \text { No fuel requirements } \\
\text { - } & \text { Best for local manufacturing }\end{array}$ & $\begin{array}{l}\text { - Difficult to install } \\
\text { - Higher structure designing } \\
\text { and project planning } \\
\text { requirements } \\
\text { - The storage of aqua is } \\
\text { fundamental during periods } \\
\text { of low winds. }\end{array}$ \\
\hline photovoltaics & $\begin{array}{ll}\text { - } & \text { Unattended operations } \\
\text { - } & \text { No costs of fuels } \\
\text { - } & \text { Ease of maintainability } \\
\text { - } & \text { Longevity } \\
\text { - } & \text { Easy installation }\end{array}$ & $\begin{array}{l}\text { - High costs of start-up } \\
\text { - The storage of aqua is } \\
\text { fundamental during cloudy } \\
\text { periods } \\
\text { - Requires skilled and } \\
\text { technical application }\end{array}$ \\
\hline Gasoline or diesel electropumps & $\begin{array}{ll}\text { - } & \text { Portable } \\
\text { - } & \text { Widely used } \\
\text { - } & \text { Low costs of capital } \\
\text { - } & \text { Easy installation }\end{array}$ & $\begin{array}{ll}\text { - } & \text { High costs of maintenance } \\
\text { - } & \text { Fume and noise pollution } \\
\text { - } & \text { Short life expectancy } \\
\text { - } & \begin{array}{l}\text { Fuel supply is expensive and } \\
\text { erratic }\end{array}\end{array}$ \\
\hline
\end{tabular}

The section below presents the background analysis of the application of $\mathrm{H} 2 \mathrm{O}$ propelling worldwide. This contribution has been organized as follows: Section II focuses on a background analysis of the research paper. Section III is the literature review section. Section IV focuses on a critical analysis of the research where photovoltaics technology for propelling aqua has been evaluated extensively. In that section, photovoltaics propelling scheme technological viability has also been done. Finally, Section V concludes the paper and provides future directions.

\section{BACKGROUND ANALYSIS}

$\mathrm{H} 2 \mathrm{O}$ propelling across the world is dependent entirely on diesel-generated or conventional current. SVP is capable of minimizing the dependency on coal, diesel-driven, and gas current. Diesel-driven photovoltaics schemes and propane schemes necessitate expensive fuels, which also come with air and noise pollution. The general upfront costs, maintenance 
costs, and operation costs, including diesel pump replacement is 2 to 4 times more than the photovoltaics. Photovoltaics are ecologically friendly and necessitate lower costs of maintenance eliminating fuel costs. Bearing in mind the deficiency of grid current in rural environments in different localities, photovoltaics schemes are a fundamental application of solar power.

Technological application is the same in various conventional propelling structures for aqua other than the fact that power is from the sun. Photovoltaics schemes are achieving much attention and significance over the past few decades due to the unavailability of current and increase in the pricing of diesel. The rate of flow of propelling aqua is based on the incident of solar radiations and the sizes of photovoltaics arrays. An effectively designed photovoltaics scheme amounts to fundamental long-term savings on the overall costs than the conventional propelling schemes. Moreover, tanks are used where there is an aqua shortage or current shortage and where the battery is considered a major electric requirement.

In developing nations, the production of current is significantly based on rain and is critically based on the absence of aqua during hotter periods. However, enough radiations from the sun are available during the summer seasons. This shows that more aqua is available to fulfill the present demands of aqua. Aqua supply schemes in township environments are based on current to effectively pump aqua to town centers. There is a high demand for aqua usage in town environments, rural environments, educational centers, and industries, which means that photovoltaics structures are required.

This research provides an analysis of the current state of research and use of solar $\mathrm{H} 2 \mathrm{O}$ propelling technologies. This analysis concentrates on the present advancement of photovoltaics pump technologies, execution assessment, optimal sizing, simulation, and modeling, including the viability of photovoltaics use on community projects. The key purpose of this contribution is to evaluate the present research condition, identify the available gaps and potential impediments in the analytical propagation of photovoltaics. The policy and strategy concern for photovoltaics promotion has also been stressed throughout this research. The section below presents a critical analysis of the relevant literature of the photovoltaics $\mathrm{H} 2 \mathrm{O}$ propelling scheme.

\section{LITERATURE REVIEW}

This section considers a critical analysis and execution evaluation of approaches utilized by different researchers. These evaluations are critical for providing much insight to researchers.

F. Hilmer, A. Ratka, K. Vajen, H. Ackermann, W. Fuhs, and O. Melsheimer in [3] have developed a critical approach for execution projection of photovoltaics schemes of directly fixed schemes in Northern Africa based on the application of computer-simulated programs. The programs established simulate hourly executions of structures daily in a given year and this focuses on various array orientations of photovoltaics. The structure established is considered capable of propelling 24 liters in a single day during summers, 21 liters during winter, and 12 during clear sky days. The evaluated photovoltaics array efficacy is from $13 \%$ in winter and $14 \%$ during summers.

M. Chaabane, W. Charfi, H. Mhiri, and P. Bournot in [4] evaluated the execution of photovoltaics H2O propelling schemes incorporating photovoltaics array, permanent electromagnet DC engines and sun-trackers, and helical rotor electropumps. From the scheme, it was seen that the execution of the structure is developed whenever MPPT and sun trackers are incorporated into structures. The evaluation of the SPB array has been done using PSPICE software. The theoretical findings were therefore verified using field tests.

R. Herbazi, Y. Kharchouf, K. Amechnoue, A. Khouya, and A. Chahboun in [5] tested and developed an algorithm to evaluate the longevity and executions of photovoltaics propelling structures without utilizing structures for storing batteries in four different locations in the United States. This structure used the mean monthly insolation of the sun input data and assessed the general monthly aqua volume that has been incorporated with simulations per hour.

B. Đurin and J. Margeta in [6] constructed the photovoltaics hydraulic ram through the incorporation of DC-to-DC buck converters, which were proving a current boost to the DC electropumps. In this scheme, no batteries or inverters were utilized, which means that the costs of maintenance were minimized. The higher no-load velocity surpasses three, 1000 revolutions in a single minute $(\mathrm{r} / \mathrm{pm})$. The finding of the no-load test indicates that the inclusion of DC engine with more radial electropump matches. Directly fixed systems without energy conditioning unit is compared to the DC-DC converter form scheme. DC engine operating current, voltage, shaft $\mathrm{r} / \mathrm{pm}$, and the rate of discharge at various pressures, moments in a day, and various moments for the structure have been improved and measured in power-driven energy output.

V. Sontake, A. Tiwari, and V. Kalamkar in [7] evaluated the executions of DC that have been directly fixed energized photovoltaics structures. The structures operate without electronic controls. Engine electropumps and their efficacy was not more than $28 \%$ that are typically for directly-fixed structures of photovoltaics. However, the structures are more effective when used on low head agricultural projects in rural environments. The efficacy of the system can be structured through the selection of the general sizes of the photovoltaics range, its orientations, and engine propelling structures.

W. Anis and H. Metwally in [8] established an approach to project lasting executions of directly-fixed photovoltaics structures. The approaches use photovoltaics components and pump engine manufacturing data according to researches. Weather data is accessed from a monthly average of straight radiations and temperatures that are ambient. The approach proposes monthly aqua propelling, which is approximately $5.1 \%$. The approach was considered because of the TRNSY 
system projects that considered hourly data on weather; and systems that designed and estimated longer executions of photovoltaics propelling structures for the American climate.

N. Obaid, E. Hashim, and N. Kasim in [9] evaluated the executions of various photovoltaics H2O propelling schemes for four various locations. J. Guggenberger, A. Elmore, and M. Crow in [10] utilize typical meteorological year (TMY) information. The research is done for three various profiles: 3 tank capacities; 2 photovoltaics module forms; 2 photovoltaics array configuration and different propelling head applicable to 2 radial electropumps and finalized, which the expense of photovoltaics generators can reduce in case a simulation program accounts for the form of electropumps, daily load profiles and propelling head profiles. The scheme can potentially by assessing personal necessities using computing programs concerning mathematical frameworks of engine electropumps and photovoltaics generators.

M. Joubert, D. Ridwan, and R. Pratiwi in [11] developed and designed a photovoltaics pump operating drip agricultural structures for arid parts consideration different designing parameters such as the sizes of electropumps, aqua necessities, diurnal variations in pump pressures because of the changes in pressure compensation and irradiance in drippers. R. Jha, A. Yadav, and D. Sharma in [12] reported that photovoltaics scheme with 160 WP photovoltaics arrays; 800W DC propelling mono block might generate 60 to $90--\mathrm{kPa}$ pressure at a side of delivery with discharges of 4 to 9 liters per hour from every dripper during various daily. The emission uniformity was $95 \%$ in fields of one hectare. It is considered that photovoltaics propelling structures necessitate wide testing in aqua harvesting tanks with low suction heads for enhancing developed orchards in desert parts.

D. Langridge, W. Lawrance, and B. Wichert in [13] evaluated the execution of photovoltaics-energized DM engines fixed with radial electropumps at various intensities of the sun that correspond to cellular temperature. Experiment findings gotten are contrasted to the figures that have been computed. It was noted that this scheme has good matching between photovoltaics arrays and electric and mechanical structure features. Analysts reported that by manual assessment (transformational orientations for any photovoltaic arrays), an output achieved is about $20.5 \%$ more than the fixed tilted photovoltaics array.

V. Tatabhatla, A. Agarwal, and T. Kanumuri in [14] evaluated the execution of photovoltaics at steady-state energized DC engine driving isolated 3-phased self-excited induction generators (SEIGs) and concluded that SEIGs are perfect load matches for photovoltaics powered DC engines with photovoltaics generators for maximum usage of efficacy. The application of SEIGs eliminates the necessity to match devices or peak energy tracker that enhances the overall cost of structures. It was considered that due to the novel torque velocity features of SEIGs, the usage efficacy is almost to the maximum at the varied insolation level that has minimal peak-energy tracks. The proposed arrangements are critical as a part of the incorporated energy structures that can be renewed

\section{CRITICAL ANALYSIS}

\section{A. photovoltaics Technology for propelling aqua}

\section{1) Current Technological State}

Photovoltaics $\mathrm{H} 2 \mathrm{O}$ propelling scheme incorporates DC/AC surfaces mounted, floating, and immersed engine propelling segments, propelling electronics, and propelling arrays. Photovoltaics arrays are incorporated and incorporated on the best structures with the present of physical tracks and automated tracks. Aqua is therefore pumped during the day before being stockpiled in tanks for usage at night or during the day. Aqua tanks are considered a storage structure and batteries are not used for photovoltaics current storage; however, for certain reliable requirements, they could be utilized.

The components utilized in photovoltaics $\mathrm{H} 2 \mathrm{O}$ propelling scheme have to conform to the local and international specifications, depending on the nation. DC that has been directly fixed electropumps was established in the engineering field in the late 1970s. Primitive photovoltaics propelling structures have disadvantages of generalized execution of structures because of the lack of effective structure designs. From that moment, industrialists have created refined products to enhance viability and processing. Constant depreciation in photovoltaics panel costs has amounted to structuring electropumps economically more viable for wide-range applications.

Directly fixed DC electropumps are modest and dependable; nonetheless, cannot effectively operate at maximized energy points of photovoltaics generators as solar variations depend on the time of the day. Nonetheless, incorporating MPPT and control/protection enhances the execution of photovoltaics electropumps (See Fig 1). Propelling structures have indicated critical developments over the past few decades. The $1 \mathrm{G}$ photovoltaics schemes utilized radial electropumps typically driven by DC engine and variable long-lasting reliability and hydraulic efficacy that vary from $20 \%$ to $40 \%$. The $2 \mathrm{G}$ photovoltaics propelling schemes utilize positive displacement electropumps, progressing the cavity pump and diaphragm electropumps; generally featured by the lower photovoltaics input energy requirement, low capital costs, and higher hydraulic efficacy of up to $70.5 \%$.

The present photovoltaics technology utilizes the electronic scheme that has further enhanced output power, structure execution, and general efficacy of structures. Controllers issue an input for tracking the level of the tanks, controlling the speed of the electropumps, and utilize MPPT technology to potentially optimize aqua. Enhancements have been considered in tracking approaches of photovoltaics arrays from manual monitoring to two-axis automated tracking structures using micro-controllers. Solar monitoring reduces the physical dimension of photovoltaics panels required for certain outputs, 
hence developing the overall yields of energy, general effectiveness of structures and investment returns. Monitoring of the photovoltaics pump and its availability in the market can lift and uplift aqua from a depth of $5 \mathrm{~m}$ to 200 with an average output of $200 \mathrm{~m}^{3}$ per day.

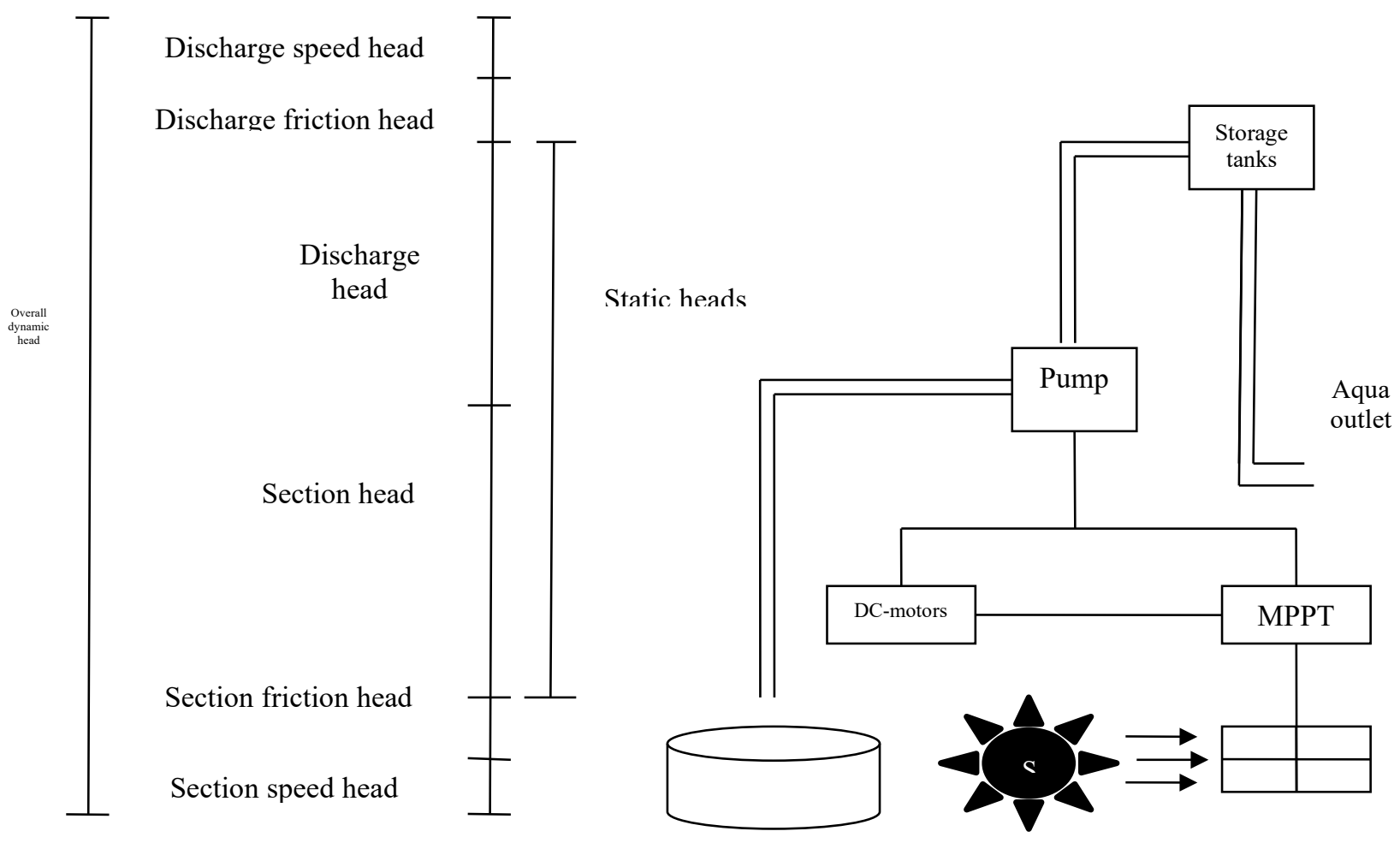

Fig 1: Schematic of directly-fixed photovoltaics H2O propelling based on MPPT

For over a decade now, fundamental developments have been seen in the helical engine pump, which is a positive displacement pump. These electropumps are considered long lasting and immersed. In addition, the electropumps are energized using similar engines just like those used in radial electropumps. The developments are evident in the controller segment for larger photovoltaics arrays in segments of $24 \mathrm{~kW}$ and $110 \mathrm{~kW}$ controllers projected in the upcoming decades. Photovoltaics module costs have drastically decreased and the availability at the rate of $\$ 0.6$ per WP in 2014 was considered $\$ 1$ in 2012 in India. This fundamentally influences the general costs of the propelling scheme since the photovoltaics module signifies about $60 \%$ to $80 \%$ of the general costs of the photovoltaics scheme. The steady enhancement in costs of gasoline and diesel price over the past few decades and the decrease in photovoltaics scheme costs make photovoltaics propelling more attractive from the fiscal perspective. Moreover, crystalline photovoltaics module with higher efficacy of $16 \%$ to $22 \%$ is available in the market and this has been the case since 2014 . In the section below, an overview of the photovoltaics, propelling technology and principle are presented.

\section{2) Principle of photovoltaics Electropumps}

Solar hydraulic ram is based on photovoltaics technology, which converts solar energy to power-driven energy that potentially electropumps aqua. Photovoltaics panels are linked to engine AC or DC that changes power-driven energies generated from photovoltaic panels from mechanical power that changes to hydraulic power by the electropumps. The capacity of photovoltaics schemes to pump aqua is the major functions of three fundamental variables: pressure, flows and energy of an electro-pump. For the designing purpose, pressures can be viewed as works finished by the electropumps in lifting particular volumes of aqua to the storage tanks. The elevation variation between storage tanks and aqua sources determines the work to be finished by the electropumps. Hydraulic ram will draw particular power that the photovoltaics array requires to supply. A schematic of a normal directly fixed DC photovoltaics H2O propelling structure with MPPT is presented in Fig 2 below. 


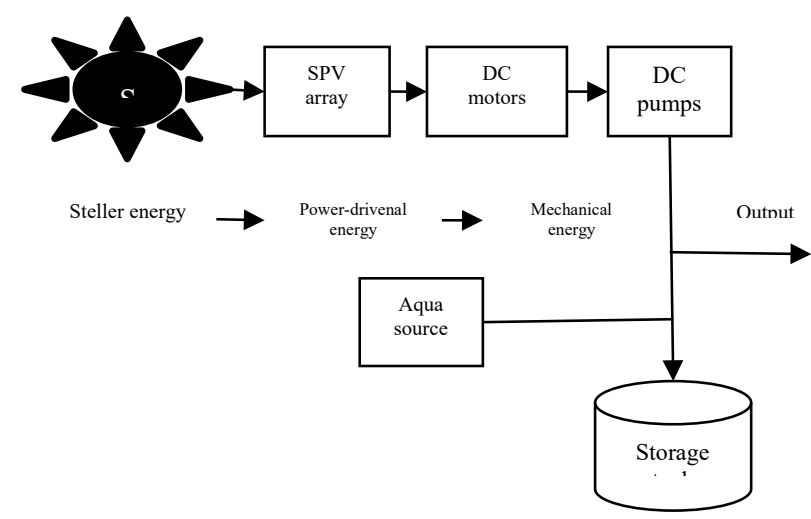

Fig 2: Representation of directly-fixed photovoltaics H2O propelling scheme

\section{3) Types of photovoltaics}

Different forms of the present configuration of directly fixed AC and DC photovoltaics propelling schemes utilized globally have been shown in Fig 3 and Fig 4.

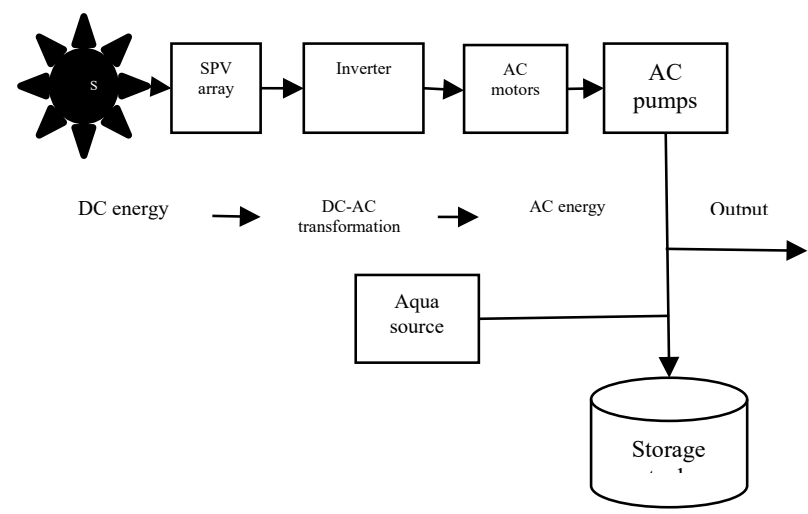

Fig 3: Presentation of photovoltaics AC H2O propelling scheme

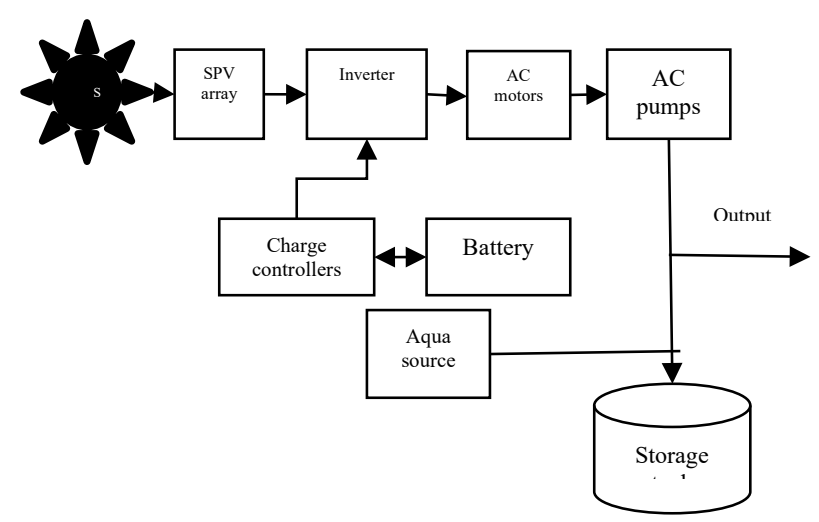

Fig 4: photovoltaics $\mathrm{H} 2 \mathrm{O}$ propelling scheme with battery storages

\section{4) Source of Aqua Supply}

The sources of aqua supply can be a spring, stream, pond, deep drilled rivers, and well. Sources of aqua have to recharge faster compared to the rate of propelling aqua. Whenever the propelling rate is more than the rate of recharging of aqua sources, reservoirs can be dry and this has to be eliminated to prevent damages to electropumps. The major variables of the scheme design are aqua reservoirs, recharge rates, costs, and volume.

5) photovoltaics Generator 
The photovoltaics generators of the electropumps incorporate photovoltaics components linked to parallel and series combinations according to engine voltage necessities. Photovoltaics components incorporate the solar cells that change solar radiations to direct current.

Voltages and current at a certain illumination for cells and diodes are provided in:

$$
i=I_{L}-I_{o}\left\{\exp \left(\frac{q}{a k T_{c}}\left(V+I R_{s}\right)-1\right\}-\frac{V+I R_{S}}{R_{s h}}\right.
$$

Whereby $I_{L}$ represents the light that is generated (current). Io represents the reverse diode and saturation currents, a represents the ideal factor that varies from a scale of one to five and shows the solar cell features deviation from ideality, $q$ represents the charges on the electrons while $\mathrm{k}$ represents the Boltzmann constant. $T_{c}$ Represents the temperatures of the cell. $R_{s h}$ Represent the resistance series and $R_{s h}$ signifies the shunt resistances. $R_{s h}$ Is will a massive figure and $R_{s}$ is with a smaller figure. In that case, it can be ignored in the analysis.

Power is extracted from the photovoltaics components and is based on climatic dynamics. These components have optimum points of operation, which are known as MPP that depends on the illumination intensity. In order to retrieve power from photovoltaics element, DC-to-DC converter are connected and controlled by MPPT. Linear current boosters are installed between the photovoltaics panel and the electropumps that turn on electropumps when the lights are low. Linear current booster requires sizing according to the propelling voltage and the output of the panel. The combiner boxes are utilized in ensuring the safety of wiring in case more than one panel has been used.

Breakers of circuits are included in boxes for prompt and safer shutoffs of panels in instances of servicing fundamental for structures. These breakers could be used just like a switch for turning pumps. Electropumps will not necessitate particular energy to produce particular amounts of flow and pressure. In that regard, photovoltaics array size needs optimization for essential power amounts. Higher capacity photovoltaics generators will permit the electropumps to launch and operate for long durations at day times under minimal insolation conditions and dynamics. However, incorporating additional panels of photovoltaics contrasted to other panels will be costly. Massive panel segment are also considered linear boosters of current energy, which means an excluded linear current booster is not essential.

\section{6) Engines Used for photovoltaics Electropumps}

Photovoltaics components produce more direct current, which means that DC engines are typically utilized in low energy solar $\mathrm{H} 2 \mathrm{O}$ propelling schemes. Solar propelling schemes, which are less than $5 \mathrm{~kW}$, utilize the DC engine. The engine comes in two forms: a DC engine that has brushes and another with no brushes. DC engine with brushes necessitates frequent maintainability because commutators and slide brushes contacting in immersed applications where electropumps have to be eliminated frequently the well for brush replacement.

\section{7) Permanent Electromagnet Synchronous Brush}

DC engine fixed with radial pump is identified as an effective alternative compared to DC engine for low energy directly fixed photovoltaics $\mathrm{H} 2 \mathrm{O}$ propelling scheme. This form of the engine is smaller and is rugged contrasted to the AC engine. The issue of cost and maintainability of DC engines have amounted to the usage of the induction engine that necessitates an inverter to be utilized between photovoltaics array and engines. photovoltaics propelling scheme based on the induction engines is maintenance-free, reliable, and rugged with enhanced efficacy and provides potentials for control approaches contrasted to DC engines.

E. Salilih, Y. Birhane, and S. Arshi in [15] have done a detailed evaluation of AC and DC engines utilized in photovoltaics propelling that indicate that the vibrant and efficient execution of permanent electromagnet DC engines is better compared to AC single-stage induction engine. The researchers also evaluated the execution features of brushes asynchronous reluctance engine governed by photovoltaic motors considering the different dimensions of insulations to propose a level and control method meant to maintain engine voltages. This is incorporated in the permitted dimensions and photovoltaics arrays meant for operation closer to MPPTs. In the analysis, it was considered that applying this form of engine leads to the enhancement in the general executions of the photovoltaics propelling scheme.

\section{8) Electropumps}

Electropumps for aqua are rated according to the voltages supplied and necessitate accessories such as switches, float valves, filters to operate effectively. Electropumps are structured from high-quality lower lead marine grades, stainless steel, and bronze and are structured for services that are free from corrosion and maintainability expense. This is also known for its endurance in harsh environment and high execution capacity. The electropump is classified into three fundamental categories based on their applications: floating hydraulic ram, surface hydraulic ram, and immersed hydraulic ram.

Immersed electropumps draw aqua from deep wells and surface electropumps that draw aqua from the shallow wells, springs, rivers tanks, and ponds while floating hydraulic ram are capable of drawing aqua from the reservoirs with changing heights and capacity. Engines and electropumps are structured in immersed floating schemes. In the surface 
schemes, engines and electropumps can be chosen differently to evaluate the execution of the scheme alongside the controllers and photovoltaics panels. Electropumps generate unique combinations of pressure and flow (higher flows and lower heats)

Widely, electropumps can be categorized under two classes concerning the operating rule: Positive displacement and dynamic electropumps. The dynamic electropumps operate through the development of a higher aqua speed and force in diffusing passage flow. Efficacy of dynamic electropumps is minimal than the positive displacement pump but with a comparatively lower maintainability requirement. A positive displacement pump operates by pressurizing fixed volumes of fluids from inlet pressure sections of the pump into discharging zones of the electropumps. The electropumps are generally larger compared to the equal capacity dynamic pump. The Radial pump and the axial pump flow are considered dynamic electropumps.

\section{a) Dynamic Electropumps}

In the radial pump, sucking of aqua happens by radial forces generated by impellers and the casing causes aqua to flow to the outlet as the impellers keep on rotating, Aqua can therefore leave with high pressure and speed compared to how it entered. Radial pump is interfaced with the panels of solar and utilized for lower head application. Radial electropumps can match the output of solar generators. The operations of these electropumps happen for long duration, including at lower dimensions of insolation, and features of the load are closer to photovoltaics MPP. Radial pump has relatively higher efficiency; however, it diminishes at lower velocities, which can be a major concern for propelling schemes at lower insolation. Radial electropumps are economical up to $79 \mathrm{~m}$, which is from shallow to medium. Axial flow pump is a dynamic pump, which utilizes the propellers to form lift actions of fluids in the pipes. The pump is normally utilized in wet-pit drainages, lower pressure agricultural, and storm aqua applications.

\section{b) Displacement Pump}

Screw electropumps and piston electropumps are known as volumetric electropumps, which are known for their different velocity torque features and are not suitable for connection to the photovoltaics panel. Whenever these electropumps are utilized, a unit for power conditioning and MPPT scheme has to be included between electropumps and solar panels. The electropumps are of the rotational impeller form that throws aqua radially over the case-shaped such that the momentum of water is changed into forces controlling lifts. In electro-pump displacement, the outputs of aqua are directly proportional to the velocity of the electropumps. However, it is mostly independent of the heads. For the screw electropumps, screws trap aqua in the suction segment of the pump case and stimulate it to the outlets. In the diaphragm (piston) electropumps, the direction and motion of the piston stimulate aqua into the chambers using inlet valves and potentially expels it to the outlets with the assistance of outlet valves.

Piston electropumps are more complex based on the movable parts and necessitate the lubrication of oil in the electropumps that might be a significant risk in the wells. Normally, these are utilized in the lower voltage (i.e. 24 to $48 \mathrm{~V}$ ) applications with the minor daily flow (i.e. $5 \mathrm{~m}^{3} /$ day) for lifts surpassing $150 \mathrm{~m}$ (maximum of $1.9 \mathrm{~m}^{3} /$ day). The choice of the electropumps for photovoltaics is based on the requirements of aqua, aqua lift heights, and the quality of aqua. An optimized solar pump is to be chosen and the one that can potentially accomplish typical flows of water and water pumping requirement for heads.

\section{B. photovoltaics Propelling Scheme Technological Viability}

\section{1) Ingenuities for Developed Nations}

Photovoltaics systems have, for many decades now, been considered viable for developed nations. This was the project launched by the World Bank and identified as the International Solar Propelling Project purposed at determining the technological and commercial viability of the electropumps. In the first phase of the project, $12 \mathrm{H} 2 \mathrm{O}$ propelling schemes (a single solar thermodynamic photovoltaics type) were tested in the Philippines in the early 1980s. Three different systems were rated. Two of them were rated $11 \%$ and five electropumps were fundamentally lower compared to the rated figures. The remaining two schemes failed to operate incorporating thermodynamic electropumps.

Even though the results had not been considered encouraging, the research showed that the technologies of photovoltaics are promising and assured significant research that focused on enhancing the scheme. In that case, the second phase of the international project was considered and incorporated 64 schemes with enhanced specifications being evaluated. The executions of these schemes were considered to be enhanced but still necessitated more development and research to enhance reliability and structure execution. It was noted that photovoltaics propelling schemes were economically applicable and viable in nations with more sunshine and the ones with increased pricing of diesel and higher overall aqua requirements throughout the year.

The World Bank published a handbook in 1984 regarding the solar H2O propelling project. Similarly, an analysis on photovoltaics electropumps was done and handout published in the Sandia National Lap in the late 1980s with frequent and subsequent analyses and revisions considered in the upcoming years. These were analyses highlighting the advantages of photovoltaics propelling schemes. Photovoltaics scheme was considered more economical and attractive than the dieselbased propelling scheme. Photovoltaics module and the Balance of Schemes expenditures have reduced extremely low since their feasibility researches have been considered as well. Photovoltaics schemes are now present, dependable, and cost-effective compared to the earlier days. 
According to an analysis done by researchers, the payback time for photovoltaics propelling schemes in Indian for four years was done, and Rs. 8.5 was compared to Rs. 13.8 for the princes of diesel-based propelling schemes. During this analysis, the feasibility of the photovoltaics generators for the power-driven supply of energy was done for $\mathrm{H} 2 \mathrm{O}$ propelling projects in township aqua resource schemes and this proved that $\mathrm{H} 2 \mathrm{O}$ propelling could efficiently be used through the application of standalone photovoltaics schemes or the interlinkage of other potential power-driven supply schemes for effective reliability. Photovoltaics scheme viability is more sensitive to the insolation amount and the utilization of energy. For instance, if the schemes' output is not completely used, the installation might not be attractive fiscally. photovoltaics is an effective and attractive alternative for developing nations such as China, India, some Asian and African countries since insolation is present and the majority of the rural population resides in remote environments.

\section{2) Indian Perspective of photovoltaics Propelling Technology}

India has about 27 million-ground hydraulic ram in their agricultural fields that can operate using diesel and current. The failure or shortage of power and the ever-advancing diesel fuel expense influence agricultural produce and crop agricultural. The implementation of photovoltaics electropumps can save considerable diesel and power-driven subsidies being given to agricultural experts. The Ministry of New and Renewable Energies initially launched solar propelling programs in India in the early 90s. During that time, approximately 13,900 electropumps were incorporated throughout India. A fresher thrust has been provided to the solar propelling programs in nations considering the introduction of Jawaharlal-Nehru Countrywide Solar missions. In the program, approximately, 3B rupees were spent on the farmers for photovoltaics installation of electropumps.

In 2015,17500 , solar-powered propelling schemes are to be incorporated with targets of $1 \mathrm{M}$ electropumps for drinking aqua and agricultural projects by this year (2021). The main purpose of this is to advance agricultural yields and minimize the overdependence on diesel for propelling aqua in the states incorporating Himachal Pradesh, Punjab, Bihar, Madhya Pradesh, and Chhattisgarh. Grants to the farmer will cover approximately $31 \%$ of the overall cost of solar $\mathrm{H} 2 \mathrm{O}$ propelling schemes limited to Rs. $57,000 / \mathrm{kWp}$ to $57,000 / 5 \mathrm{kWp}$ capacity of the components for the agricultural schemes and other aims.

The participating states would require issuing similar grants, which represent about $15 \%$ of the overall costs. Agricultural professionals have to cater for the remaining costs. India has issued guidelines regarding the manufacturing of photovoltaics according to the global standards with modernized testing processes, which ensures the quality of products with effective execution and longer life. Multi/monocrystalline silicon photovoltaics module according to IEC-61215 equivalent national and global standards are to be utilized in electropumps. The efficacy of photovoltaics module has to minimize $14 \%$ and filling factor has to be more than $69 \%$. DC and AC engine electropumps are set suitable for photovoltaics $\mathrm{H} 2 \mathrm{O}$ propelling schemes and $\mathrm{DC}$ to $\mathrm{AC}, \mathrm{DC}$ to $\mathrm{AC}$ converters according to requirements is to be utilized.

\section{CONCLUSIONS AND FUTURE DIRECTIONS}

This contribution has evaluated present status of photovoltaics $\mathrm{H} 2 \mathrm{O}$ propelling scheme technology analysis and application. The research concentrates on updates on solar $\mathrm{H} 2 \mathrm{O}$ propelling technologies, execution evaluation analyses done worldwide, optimal sizing approaches, degradation of photovoltaics generator supply energy to electropumps, economic assessment, ecological aspects and the advancements in materials over the past few decades, and efficiency enhancements of SOV technology, including the experiences of utilizing photovoltaics electropumps globally. Regarding the research, the major conclusions, in this case, are: (I) photovoltaics $\mathrm{H} 2 \mathrm{O}$ propelling technologies are dependable and economically viable alternatives to diesel and power-driven hydraulic ram for agricultural for agricultural products. (ii) Photovoltaics $\mathrm{H} 2 \mathrm{O}$ propelling for community, rural and township aqua institutions and supplies is another possible practicable fragment; however, it is not widely used. Remote inaccessible areas with no grid energy also require specialized attention. The parts are still based on conventional energy and diesel-centered propelling scheme amounting to enhanced recurring expenses to users. (iii) Considering the higher installation costs of photovoltaics hydraulic ram certainly for larger agricultural schemes and aqua supply projects, incentives are essential to be given by federations. The technology discussed in this paper is more attractive to power-driven and diesel $\mathrm{H} 2 \mathrm{O}$ propelling schemes. (iv) Dynamics influencing the efficiency and execution-enhancing technologies utilize highly effective photovoltaics components incorporating bifacial components and degradation of photovoltaics generators need further researches to structure affordable schemes, have enhanced execution and lifespan. Electropumps have proved to be an effective alternative for township agricultural H2O-propelling applications in developing counties.

\section{References}

[1]. J. Roger and C. Maguin, "Photovoltaic solar panels simulation including dynamical thermal effects", Solar Energy, vol. 29, no. 3, pp. 245-256, 1982. Available: $10.1016 / 0038-092 \times(82) 90210-9$.

[2]. A. David, "U.S. Solar Photovoltaic (PV) Cell and Module Trade Overview", SSRN Electronic Journal, 2011. Available: 10.2139/ssrn.1873251.

[3]. F. Hilmer, A. Ratka, K. Vajen, H. Ackermann, W. Fuhs and O. Melsheimer, "Investigation of a directly coupled photovoltaic pumping system connected to a large absorber field", Solar Energy, vol. 61, no. 2, pp. 65-76, 1997. Available: 10.1016/s0038-092x(97)00053-4.

[4]. M. Chaabane, W. Charfi, H. Mhiri and P. Bournot, "Performance evaluation of concentrating solar photovoltaic and photovoltaic/thermal systems", Solar Energy, vol. 98, pp. 315-321, 2013. Available: 10.1016/j.solener.2013.09.029.

[5]. R. Herbazi, Y. Kharchouf, K. Amechnoue, A. Khouya and A. Chahboun, "Solar Photovoltaic Cell Parameters Extraction Using Differential Evolution Algorithm", Proceedings, vol. 63, no. 1, p. 43, 2020. Available: 10.3390/proceedings2020063043. 
[6]. B. Đurin and J. Margeta, "Analysis of the Possible Use of Solar Photovoltaic Energy in Urban Water Supply Systems", Water, vol. 6, no. 6, pp. 1546-1561, 2014. Available: 10.3390/w6061546.

[7]. V. Sontake, A. Tiwari and V. Kalamkar, "Experimental investigations on the seasonal performance variations of directly coupled solar photovoltaic H2O pumping system using centrifugal pump", Environment, Development and Sustainability, 2020. Available: 10.1007/s10668020-00965-x.

[8]. W. Anis and H. Metwally, "Dynamic performance of a directly coupled PV pumping system", Solar Energy, vol. 53, no. 4, pp. 369-377, 1994. Available: 10.1016/0038-092x(94)90040-x.

[9]. N. Obaid, E. Hashim and N. Kasim, "Performance Analyses of 15 kW Grid-Tied Photo Voltaic Solar System Type under Baghdad city climate", Journal of Engineering, vol. 26, no. 4, pp. 21-32, 2020. Available: 10.31026/j.eng.2020.04.02.

[10]. J. Guggenberger, A. Elmore and M. Crow, "Predicting performance of a renewable energy-powered microgrid throughout the United States using typical meteorological year 3 data", Renewable Energy, vol. 55, pp. 189-195, 2013. Available: 10.1016/j.renene.2012.12.001.

[11]. M. Joubert, D. Ridwan and R. Pratiwi, "Performance of Groundwater Irrigation System on Drip Irrigation Using Solar Water Pump", Jurnal Irigasi, vol. 11, no. 2, p. 125, 2017. Available: 10.31028/ji.v11.i2.125-132.

[12]. R. Jha, A. Yadav and D. Sharma, "Second law analysis of the $160 \mathrm{Wp}$ standalone solar photovoltaic system", International Journal of Sustainable Energy, vol. 38, no. 9, pp. 904-917, 2019. Available: 10.1080/14786451.2019.1616733.

[13]. D. Langridge, W. Lawrance and B. Wichert, "Development of a photo-voltaic pumping system using a brushless d.c. motor and helical rotor pump", Solar Energy, vol. 56, no. 2, pp. 151-160, 1996. Available: 10.1016/0038-092x(95)00077-5.

[14]. V. Tatabhatla, A. Agarwal and T. Kanumuri, "Performance enhancement by shade dispersion of Solar Photo-Voltaic array under continuous dynamic partial shading conditions", Journal of Cleaner Production, vol. 213, pp. 462-479, 2019. Available: 10.1016/j.jclepro.2018.11.015.

[15]. E. Salilih, Y. Birhane and S. Arshi, "Performance analysis of DC type variable speed solar pumping system under various pumping heads", Solar Energy, vol. 208, pp. 1039-1047, 2020. Available: 10.1016/j.solener.2020.08.071. 